\title{
A Clinical Report on Receptive Vocabulary Skills in Cochlear Implant Users
}

\author{
P. W. Dawson, P. J. Blamey, S. J. Dettman, E. J. Barker, and G. M. Clark
}

Objective: The aim was to measure the rate of vocabulary acquisition for cochlear implant users and compare the pre- and postoperative rates with published data for other groups with normal or impaired hearing. The hypothesis was that the postoperative rate would be greater than the preoperative rate.

Design: The Peabody Picture Vocabulary Test (PPVT) was administered to 32 children, adolescents, and prelinguistically deafened adults implanted with the 22-electrode cochlear implant. Age at implantation ranged from 2 yr $6 \mathrm{mo}$ to $20 \mathrm{yr}$ and implant use ranged from 6 mo to 7 yr $8 \mathrm{mo}$.

Results: The group mean postoperative performance at various postoperative intervals was significantly higher than mean preoperative performance. Single-subject data indicated statistically significant gains over time on this test for 13 of the subjects. The mean postoperative rate of vocabulary acquisition of $\mathbf{1 . 0 6}$ times the rate for normally hearing children was significantly greater than the mean preoperative rate of 0.43 .

Conclusions: These rates of improvement were in accord with previous reports on smaller numbers of implant users, but could not be attributed unambiguously to use of the implant because no control group was used for this clinical work. Variables such as age at implantation, duration of profound deafness, communication mode, and speech perception skill failed to significantly predict rate of improvement on the PPVT.

(Ear \& Hearing 1995;16;287-294)

Profound hearing loss in children has serious implications for the development of oral/aural communication skills. It has been shown that substantial delays in receptive and expressive language can occur as a result of prelinguistic or early onset deafness (de Quiros, 1980; Nober \& Nober, 1977; Quigley \& Paul, 1984).

There are numerous papers indicating that cochlear implants can improve speech perception in children (e.g., Busby et al., 1989; Dawson et al., 1992; Geers \& Moog, 1988; Luxford et al., 1988;

Cochlear Implant Clinic (P.W.D., S.J.D., E.J.B.), Royal Victorian Eye and Ear Hospital, East Melbourne, Australia; Department of Otolaryngology (P.J.B., G.M.C.), University of Melbourne, East Melbourne, Australia
Osberger et al., 1991; Robbins, Osberger, Miyamoto, Renshaw, \& Carney, 1988; Staller, Dowell, Beiter, \& Brimacombe, 1991; Tyler, 1990). An important question is whether children with cochlear implants can integrate the auditory information provided by the device into both receptive and expressive spoken language. This may be especially important in the first $6 \mathrm{yr}$ of life when the speech and language skills of normally hearing children develop rapidly. Early intervention with an appropriate hearing prosthesis and intensive training may be critical for the young profoundly hearing-impaired child to learn language effectively.

There are a small number of studies reporting improvements over time in language skills for implanted children (Busby et al., 1989; Dowell et al., 1991; Geers \& Moog, 1991; Hasenstab \& Tobey, 1991; Kirk \& Hill-Brown, 1985). Each of these assessed receptive vocabulary using the Peabody Picture Vocabulary Test-Revised (PPVT; Dunn \& Dunn, 1981). Comparative details for these studies are provided in Table 1.

The PPVT enables the hearing-impaired child's score to be interpreted with reference to the normally hearing child's performance, that is, the age of normally hearing children receiving the same mean score as the deaf child is referred to as an equivalent age (EA). It is important to determine whether there is a significant gain in equivalent age for the hearing-impaired child over time. A significant improvement may occur and be associated with either a small or large overall change in EA over a particular time period. It is therefore also important to consider the rate of improvement; the change over time in equivalent age divided by the change in chronological age. A rate of 1.00 represents the "normal" rate of learning (i.e., an equal change of equivalent age and chronological age in a given time period).

Table 1 provides the mean rate of improvement from pre- to post implantation for patients in five studies on implanted children. The rates were assessed over periods of implant use ranging from 6 to $30 \mathrm{mo}$, depending on the study and the particular child. The rate provided for the Kirk and Hill-Brown (1985) study is based on an assessment at an unspecified time before implantation. In calculating the rate of improvement, we have assumed the assessment was 1 mo prior to implantation. If the 
TABLE 1. Previously published PPVT results for hearing impaired children.

\begin{tabular}{|c|c|c|c|c|c|c|}
\hline Reference & Device & No. of children & Age range & $\begin{array}{c}\text { Duration of } \\
\text { deafness }\end{array}$ & $\begin{array}{l}\text { Duration of } \\
\text { implant use }\end{array}$ & $\begin{array}{l}\text { PPVT rate of } \\
\text { improvement }^{a}\end{array}$ \\
\hline Kirk and Hill-Brown (1985) & 3M implant & 78 & $3-18$ yr & $3-18 y r$ & $\begin{array}{l}6 \mathrm{mo} \\
12 \mathrm{mo}\end{array}$ & $\begin{array}{l}1.0(N=11)^{b} \\
1.8(N=6)^{b}\end{array}$ \\
\hline Busby et al. (1989) & Nucleus implant & 2 & $5-10 \mathrm{yr}$ & $2-7 \mathrm{yr}$ & $18-27 \mathrm{mo}$ & 1.3 \\
\hline Dowell et al. (1991) & Nucleus implant & 4 & $5-13 \mathrm{yr}$ & $2-8 \mathrm{yr}$ & $6-30 \mathrm{mo}$ & 1.0 \\
\hline Geers and Moog (1991) & Nucleus implant & 3 & $5-10 y r$ & $5-10 y r$ & $12 \mathrm{mo}$ & 0.6 \\
\hline Hasenstab and Tobey (1991) & Nucleus implant & 4 & $2-7 \mathrm{yr}$ & $1-5 \mathrm{yr}$ & $12 \mathrm{mo}$ & 2.6 \\
\hline \multirow[t]{2}{*}{ Boothroyd, Geers, and Moog (1991) } & Hearing aids & $123($ PTA $>105 \mathrm{~dB})$ & $4-18 \mathrm{yr}$ & Not known & Not applicable & 0.43 \\
\hline & & $188(90<$ PTA < $104 \mathrm{~dB})$ & $4-18$ yr & Not known & Not applicable & 0.60 \\
\hline \multirow[t]{2}{*}{ Geers and Moog (1988) } & Hearing aids & 44 & $8-14$ yr & $8-14 \mathrm{yr}$ & Not applicable & 0.51 \\
\hline & & 100 & $16-18 \mathrm{yr}$ & $16-18 y r$ & Not applicable & 0.56 \\
\hline
\end{tabular}

${ }^{a}$ Rates of improvement for the implant studies were calculated from the published data by dividing the changes in equivalent age by the corresponding changes in chronological age. The rates for hearing aid users are quoted directly from the references.

${ }^{b}$ This is a subgroup from the group of 78 children with age and duration of deafness ranging from 3 to $18 y r$.

assessment was actually more than 1 mo preoperative, the true rate of improvement would be lower than the estimate given in Table 1 . The Geers and Moog (1991) study is unique in that it used control groups of matched patients to allow a comparison of the implant's contribution to language gains relative to the contributions of a conventional hearing aid and a two-channel vibrotactile aid (the Tactaid II). The hearing aid and tactile users who were matched on various parameters showed similar gains on the PPVT and other language tests.

Table 1 also provides details of two studies which report group learning rates on the PPVT for profoundly hearing-impaired children using hearing aids. In the study by Geers and Moog (1988) the younger group of 44 children enrolled in an oral program at the Central Institute for the Deaf (CID) was grouped according to one of four speech perception categories: 1) no speech perception, 2) pattern perception, 3) some word recognition, and 4) consistent word recognition. There was a gradual increase in the average PPVT learning rate from 0.37 for children in category 1 to 0.68 for those in category 4 . The group of 100 adolescents from oral and mainstream programs in America, was grouped according to categories 2 to 4 . There was little difference in rates of learning for these subgroups of adolescents. Boothroyd, Geers, and Moog (1991) reported faster learning rates for a group of children with unaided pure-tone average (PTA) thresholds between 90 and $104 \mathrm{~dB}$ HL, compared with another group with PTA thresholds of $105 \mathrm{~dB}$ HL or more.

In summary, the previous studies in Table 1 suggest that vocabulary acquisition for profoundly hearing-impaired children using cochlear implants may be faster than for comparable groups of children using hearing aids. This suggestion requires further substantiation because it is based on small numbers of implanted children, often selected from larger groups, and observed over time periods no longer than $1 \mathrm{yr}$ in most cases.

This paper reports the PPVT results for all children (32 patients up to February 1994) who had received postoperative assessments over periods from 6 mo to $7 \mathrm{yr}$ at the Royal Victorian Eye and Ear Hospital Cochlear Implant Clinic. This is the first quantitative language data reported for a large group of multichannel cochlear implant users. The evaluations were conducted in the course of the clinical management of these patients, and were designed to measure the individuals' performance over time from pre- to postoperative test periods as well as average group performance. The ancillary question of what contribution the implant made to any change observed (compared with a control group using hearing aids or alternative assistive devices) was not considered directly, but comparisons with data reported for normally hearing and hearingimpaired children can be made. The following specific questions were investigated:

a) Did the group mean performance show improvement from pre- to postoperative test periods?

b) Was the mean postoperative rate of vocabulary acquisition greater than the mean preoperative rate?

c) Did scores improve significantly over time from pre- to postoperative test intervals for individuals?

d) How do individuals' rates of improvement compare to the "normal" rate?

d) Could individual differences in learning rates on the PPVT be accounted for by factors such as duration of profound deafness prior to implantation?

\section{MeThod}

\section{Patients}

Table 2 summarizes patient details for 32 subjects. The group includes two prelinguistically deafened adults implanted at approximately $20 \mathrm{yr}$ of age. 
TABLE 2. Patient details. Ages and durations are shown in years and months.

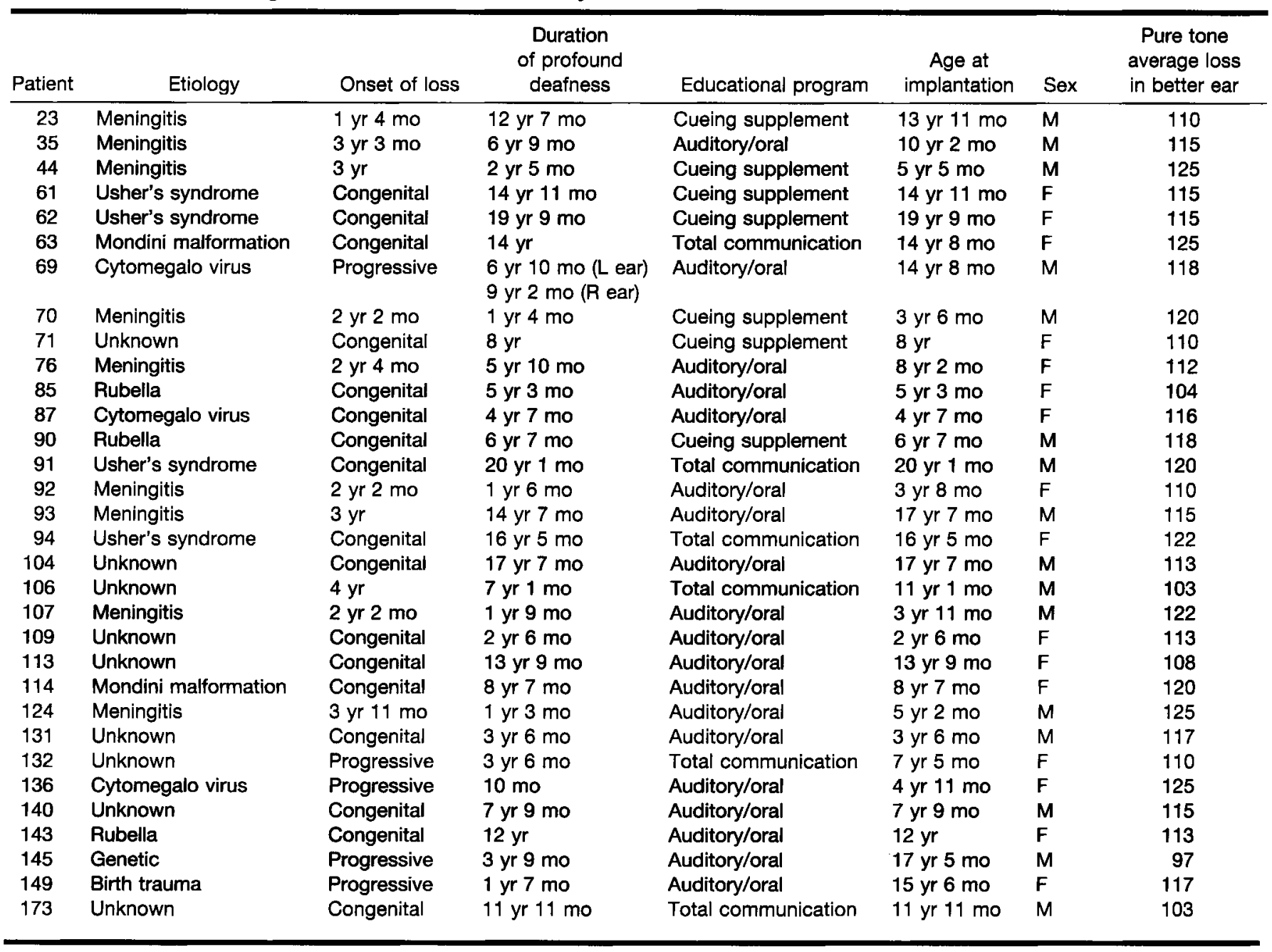

The word "child" in this paper refers to a patient under $18 \mathrm{yr}$ at implantation. The word "patient" refers to implant users who may be either adults or children. The numbering of the patients is according to the chronological order in which they were implanted. Language results for children $35,44,71$, and 76 have been reported previously (Busby et al., 1989; Dowell et al., 1991). Some of the earlier data are repeated in this paper for comparison with other patients and more recent data for these children are also included.

The mean pure tone average hearing loss was 115 $\mathrm{dB} H \mathrm{HL}$ in the better ear preoperatively. The preoperative evaluation was conducted using high-gain postauricular hearing aids that the patients had been using regularly prior to implantation. Patients' preoperative aided hearing thresholds were out of the $70 \mathrm{~dB}$ SPL speech range (Byrne, 1977) for frequencies above $1.5 \mathrm{kHz}$, except for children 85 , 143,145 , and 173 who had thresholds in the speech range at $2 \mathrm{kHz}$. Seven children $(44,87,92,93,113$, 114 , and 143) used a tactile device in addition to a hearing aid prior to implantation. Children 113 and 143 used a multichannel electrotactile speech processor ("Tickle-Talker," Cowan et al., 1990) and Child 44 used the single-channel vibrotactile Tactaid I (Audiological Engineering, Somerville MA). The other children used the two-channel vibrotactile Tactaid II. Seven children $(76,85,109,113$, 131,140 , and 173) continued to use a hearing aid on the unimplanted ear following surgery. Patient 91 wore an aid on the unimplanted ear for 1 yr postimplantation after which time he chose not to wear it. Child 143 rejected a hearing aid on the unimplanted ear 3 mo postimplantation. Patient 145 was unable to wear an aid on the unimplanted ear due to recurrent otitis media. All postoperative PPVT assessments for these patients have been conducted in the combined condition (implant plus hearing aid). Separate evaluations of the implant and hearing aid were not conducted in order to reduce the assessment time and because it was considered more relevant to assess changes under conditions used in everyday communication. 
Each of the patients was implanted with the 22-electrode cochlear prosthesis (Clark et al., 1987). Twenty-nine patients had 15 or more electrode channels activated. Patients 44,63, and 93 had 7, 9, and 5 electrode channels activated, respectively, due to partial insertion and unpleasant sensations on some electrodes. For most patients the initial speech processing strategy encoded the fundamental frequency (F0) as pulse rate, estimates of the first and second formant frequencies (F1 and F2) as electrode positions and amplitude as current level (Blamey, Dowell, Clark, \& Seligman, 1987). Soon after October 1989, these patients were changed over to the MSP processor and a multipeak strategy which encodes F0, F1 and F2, as well as the amplitude of three high frequency bands: 2.0 to $2.8 \mathrm{kHz}, 2.8$ to 4 $\mathrm{kHz}$, and frequencies above $4 \mathrm{kHz}$, onto three fixed basal electrode positions (Dowell, Whitford, Seligman, Franz, \& Clark, 1990). This additional information helps in the identification of voicing distinctions and fricatives (Blamey \& Tartter, 1992). Patients 44, 63, and 93 used the MSP processor without the multipeak strategy, because of their significantly reduced numbers of electrodes.

\section{Habilitation}

The patients received auditory/oral speech and language habilitation in addition to that provided in their educational programs. Usually, individual sessions of approximately $1.5 \mathrm{hr}$ were provided at regular intervals throughout pre- and postoperative periods. The habilitation had a strong focus on the use of audition in the development of spoken communication, incorporating the development of speech perception and speech production skills and language. A parent attended some therapy sessions and was guided in how to optimize the use of audition in his/her interaction with the child. There was also a close liaison with teachers in the child's educational setting. Further details are given by Mecklenburg et al. (1990) and Rowland, Dawson, Dettman, and Clark (1992).

\section{Assessments}

The Peabody Picture Vocabulary Test-Revised (Dunn \& Dunn, 1981) was used to estimate receptive vocabulary. It consists of 175 words ordered in a hierarchy of increasing linguistic difficulty. The task requires an understanding of concrete words, abstract words and concepts such as "measuring." The test words were presented in an audition plus vision (AV) mode and the patient pointed to one of four pictorial choices. The written word was provided frequently for the more complex words whenever the patient was hesitant in his/her response.

It was desirable to obtain a preoperative baseline and several postoperative measurements for each patient, but in some cases this was not possible given clinical constraints.

\section{Data Analysis}

Analysis of group data looked at gains in equivalent age as a function of postimplantation periods. The Wilcoxon matched-pairs signed-ranks test was used with a one-tailed criterion to determine whether the group mean postoperative performance would be superior to the group mean preoperative performance.

A nonparametric statistic, the Spearman rank correlation coefficient $\left(r_{\mathrm{s}}\right)$ was used to determine whether changes in equivalent age were significantly correlated with changes in chronological age for 25 individuals with more than two assessments. The overall rate of change was computed for all patients. This rate considered the most recent postoperative score minus the latest preoperative score or the overall change in the postimplantation period for those patients with no preoperative data (patients $61,69,90,92,107,109$, and 131). These seven patients were first assessed within 6 mo following cochlear implantation. The overall rate of change was chosen in preference to slope coefficients of linear regression lines given that seven patients had too few data points for regression line coefficients to be determined.

A multivariate regression analysis was conducted on the PPVT data to determine what factors accounted for variance in performance between individuals. The overall rate of change was used as the dependent variable in the analysis. The factors; duration of implant experience, age at implantation, duration of profound deafness, age at onset of profound loss, communication mode (oral/aural or total communication), and speech perception skill were the independent variables used. The latter was the patient's percentage score obtained on the Picture Vocabulary Test (Plant, 1984) at the time of the most recent postoperative PPVT assessment. This test requires the recognition of monosyllabic words in a closed-set 12-alternative forced-choice format. The items in the test are: "shoe, fork, tree, car, bird, key, dog, book, duck, bed, hat, fish." Each item was presented twice and the patient responded by pointing to pictures. The authors chose this particular test for two reasons: first, it is sensitive to differences within the group tested; and second, a closedset test is more likely to provide a measure of 
TABLE 3. Group mean PPVT equivalent ages obtained preoperatively and at various stages postoperatively.

\begin{tabular}{|c|c|c|c|c|c|c|c|c|c|c|}
\hline \multirow[b]{2}{*}{ Postimplant interval (mo) } & \multirow[b]{2}{*}{$N^{p}$} & \multicolumn{3}{|c|}{ Chronological age (yr) } & \multicolumn{4}{|c|}{ Equivalent age (yr) } & \multicolumn{2}{|c|}{ Improvement rate } \\
\hline & & Preimplant & Postimplant & Increase $e^{b}$ & Preimplant & Postimplant & Increase $e^{b}$ & $p^{c}$ & Preimplant $^{d}$ & Postimplant $^{\ominus}$ \\
\hline 6 & 14 & 9.9 & 10.7 & 0.8 & 3.5 & 4.3 & 0.8 & 0.003 & 0.35 & 1.01 \\
\hline $12-18$ & 20 & 11.1 & 12.5 & 1.4 & 4.1 & 5.4 & 1.3 & 0.0005 & 0.37 & 0.93 \\
\hline $24-30$ & 16 & 10.4 & 12.9 & 2.5 & 4.5 & 6.8 & 2.3 & 0.001 & 0.43 & 0.92 \\
\hline $36-42$ & 8 & 8.4 & 11.7 & 3.3 & 3.2 & 6.1 & 2.9 & 0.025 & 0.38 & 0.88 \\
\hline Most recent assessment ${ }^{f}$ & 32 & $10.4^{a}$ & 13.2 & 2.8 & $4.4^{a}$ & 6.8 & 2.4 & 0.0005 & 0.42 & 0.87 \\
\hline
\end{tabular}

${ }^{a} N$ is the number of patients tested at each stage.

b The increase is equal to the mean postimplant age minus the mean preimplant age.

'The $\rho$ value refers to the significance of the Wilcoxon matched-pairs signed-ranks test comparing pre- and postimplant equivalent ages.

${ }^{d}$ The preimplant improvement rate is equal to the preimplant equivalent age divided by the preimplant chronological age.

a The postimplant improvement rate is equal to the increase in equivalent age divided by the increase in chronological age.

${ }^{f}$ For seven of the patients for whom there was no preoperative data, the earliest postoperative assessment was included with the "preimplant" data and compared with the most recent assessment.

perception that is independent of vocabulary knowledge than an open-set test.

\section{Results}

\section{Group Results}

Most patients had equivalent ages well below their chronological ages at all pre- and postoperative evaluations, as expected from previous studies of the receptive vocabulary of hearing-impaired children (see Introduction). Table 3 indicates that the group mean equivalent age preimplantation was less than half the group mean chronological age preimplantation. At the most recent postoperative evaluation, the group mean equivalent age had increased to just over half the group mean chronological age. Only three children (44, 76 and 93) had reached ageappropriate levels by this evaluation, and it is interesting to note that all three were adventitiously deafened through meningitis between the ages of 2 yr 4 mo and 3 yr.

The mean group PPVT performance for the 32 patients on the most recent postoperative assessment was significantly greater than that on the most recent preoperative assessment or earliest postoperative assessment $(p<0.001$ ) (see Table 3). The change in mean equivalent age over time (2.4 yr) was close to the change in mean chronological age over time (2.7 yr), indicating a rate of improvement of 0.87 for the group. The preoperative group rate of improvement was 0.42 , calculated by dividing the mean equivalent age at the preimplant assessment by the mean chronological age at the same assessment. Analyses were also computed for subgroups of patients to compare preoperative scores with scores at varying postoperative periods. At all intervals assessed (from the 6 mo interval to the 36 to 42 mo interval) postoperative performance significantly exceeded preoperative performance. Postoperative group rates of improvement were more than double the preoperative rates of improvement for the same groups.

\section{Individual Results}

Overall rate of learning vocabulary is shown for each of the 32 patients in Table 4 . Preoperative learning rates were calculated by dividing the patient's most recent preoperative equivalent age by the chronological age at the time of testing. If no preoperative score was available, the first postoperative equivalent age was used instead. No patient showed a learning rate greater than 1.00 preoperatively, and the average rate was 0.43 , equal to the group rate found for hearing aid users with similar hearing losses by Boothroyd et al. (1991). Postoperatively, nine patients showed an overall rate of improvement which exceeded the normal rate of vocabulary acquisition $(44,69,76,85,93,104,113$, 149 , and 173). Seven patients $(23,35,71,92,109$, 143 , and 145) improved at a rate ranging between 0.67 and 0.90 . Seven patients revealed a learning rate between one-third and two-thirds of the normal rate $(70,90,94,107,114,124$, and 136). Finally, nine patients improved at a rate less than a third of the normal rate $(61,62,63,87,91,106,131,132$, and 140). The mean postimplant individual rate of improvement of 1.06 was significantly higher than the mean preimplant individual rate of improvement (Wilcoxon Signed Rank Test, $p<0.05$ ).

Dunn and Dunn (1981) have estimated the testretest reliability of raw scores in the PPVT to be between four and eight items across the age range 2 $\mathrm{yr} 6 \mathrm{mo}$ to $40 \mathrm{yr}$. This is a variability of up to $6 \mathrm{mo}$ in equivalent age at the age of $7 \mathrm{yr}$, but corresponds to a much greater variability in equivalent age for ages over $17 \mathrm{yr}$. The large rate of increase in equivalent age for patient 93 must be qualified in light of this. The learning rate for child 69 may also be artificially inflated by a large apparent change over a very short time. 
TABLE 4. Rates of vocabulary acquisition, significance of the correlation coefficient of equivalent age with chronological age, and speech perception score for individual children.

\begin{tabular}{|c|c|c|c|c|}
\hline Patient no. & $\begin{array}{l}\text { Preimplant } \\
\text { rate }\end{array}$ & $\begin{array}{l}\text { Postimplant } \\
\text { rate }\end{array}$ & $\begin{array}{l}\text { Spearman } \\
\text { significance }\end{array}$ & $\begin{array}{l}\text { Perception } \\
\text { score (\%) }\end{array}$ \\
\hline 23 & 0.39 & 0.78 & $p<0.05$ & 8 \\
\hline 35 & 0.53 & 0.87 & $p<0.05$ & 67 \\
\hline 44 & 0.38 & 1.65 & $p<0.05$ & 100 \\
\hline 61 & 0.35 & 0.03 & NS & 63 \\
\hline 62 & 0.24 & -0.14 & NS & 8 \\
\hline 63 & 0.41 & -0.06 & NS & 17 \\
\hline 69 & 0.41 & 5.50 & $a$ & 100 \\
\hline 70 & 0.59 & 0.33 & $p<0.001$ & 100 \\
\hline 71 & 0.48 & 0.76 & $p<0.05$ & 92 \\
\hline 76 & 0.69 & 1.89 & $p<0.001$ & 54 \\
\hline 85 & 0 & 1.02 & $p<0.01$ & 79 \\
\hline 87 & 0.48 & 0.25 & NS & 50 \\
\hline 90 & 0.44 & 0.34 & NS & 100 \\
\hline 91 & 0.23 & -0.53 & NS & 21 \\
\hline 92 & 0.37 & 0.90 & $p<0.001$ & 100 \\
\hline 93 & 0.97 & 6.19 & $\mathbf{a}$ & 29 \\
\hline 94 & 0.40 & 0.60 & a & 17 \\
\hline 104 & 0.23 & 1.70 & $p<0.001$ & 8 \\
\hline 106 & 0.33 & 0.09 & $p<0.001$ & 50 \\
\hline 107 & 0.39 & 0.46 & NS & 83 \\
\hline 109 & 0.79 & 0.80 & NS & 96 \\
\hline 113 & 0.37 & 2.80 & $p<0.001$ & 79 \\
\hline 114 & 0.35 & 0.36 & $p<0.001$ & 58 \\
\hline 124 & 0.62 & 0.54 & NS & 83 \\
\hline 131 & 0.53 & 0.31 & $a$ & 100 \\
\hline 132 & 0.30 & 0.22 & NS & 4 \\
\hline 136 & 0.40 & 0.56 & $p<0.05$ & 92 \\
\hline 140 & 0.29 & 0.18 & NS & 75 \\
\hline 143 & 0.56 & 0.88 & $a$ & 92 \\
\hline 145 & 0.57 & 0.71 & a & 96 \\
\hline 149 & 0.27 & 2.50 & NS & 63 \\
\hline 173 & 0.47 & 1.33 & a & 63 \\
\hline Mean & 0.43 & 1.06 & & 64 \\
\hline Standard deviation & 0.18 & 1.46 & & 33 \\
\hline
\end{tabular}

"a" indicates insufficient data for Spearman correlation analysis. NS indicates a nonsignificant correlation between chronological age and equivalent age. When a significant p value occurs, this indicates that the rate of improvement is significantly greater than zero, and a consistent improvement has occurred over the postimplantation period.

For seven of the patients, only two data points were available. The Spearman rank correlation coefficient was computed for the 25 patients who had more than two data points. Table 4 indicates that 13 showed statistically significant, positive associations between changes in equivalent age and changes in chronological age.

A forward stepwise regression analysis revealed that none of the variables investigated, duration of implant use, duration of profound deafness, age at implantation, age at onset of profound loss, perception ability, and communication mode, was a significant predictor of individuals' overall rate of change in performance on the PPVT. Age at implantation showed a slight, positive but nonsignificant correlation with rate of change $(r=0.257)$. In contrast, the most recent postimplantation equivalent age score was found to be significantly correlated with age at implantation $(r=0.402, p<0.05)$. Perception skill was not associated with rate of vocabulary growth. The speech perception score was however significantly correlated with age at implantation $(r=$ $-0.60, p<0.001)$, duration of profound deafness $(r=-0.67, p<0.001)$ and mode of communication $(r=-0.52, p<0.01)$.

\section{Discussion}

Results were similar to previous studies of vocabulary growth in implanted children in that most patients were considerably delayed in their receptive vocabulary both pre- and postoperatively. In accordance with the findings of Kirk and Hill-Brown (1985), there were however significant group improvements (mean postoperative minus mean preoperative scores) that were consistently observed at varying postoperative test periods.

The mean individual rate of improvement of 1.06 fell within the range of average rates of improvement for smaller groups of implanted children in other studies (see Table 1). About half of the patients revealed rates of improvement that were greater than two-thirds of the normal rate, but the remaining patients improved at less than two-thirds of the normal rate. It should be noted that some of the patients who showed high rates of PPVT growth had only two data points and so no individual correlation analysis was possible. Their results will be more convincing if additional postoperative assessments show further gains in equivalent age and significant correlations with changes in chronological age are shown.

The gains shown by patients on the PPVT cannot be solely attributed to the implant in conjunction with training. The lack of a control group of nonimplanted hearing-impaired children means that we cannot tease out the effects of maturation and other variables on PPVT scores. In contrast to the finding by Geers and Moog (1988) for hearing aid users aged 8 to 14 yr reported in the Introduction, higher rates of vocabulary growth were not associated with higher scores on a closed-set word perception task for this group of patients. This study's results are more compatible with the further finding by Geers and Moog of a less distinct relationship between word recognition skills and rate of vocabulary acquisition for a group of 100 adolescents aged 16 to $18 \mathrm{yr}$. On the other hand, one cannot conclude from the present study that the perceptual information offered by the implant was irrelevant to gains on the PPVT. Some improvement in perception may combine advantageously with other factors to facilitate vocabulary growth: factors such as language train- 
ing in the educational setting, intelligence, and improvements in lip-reading and reading skills. It must be remembered that the task was presented audiovisually and at times with a written supplement. In contrast to the study by Kirk and HillBrown (1985), growth in sign language proficiency could have had only an indirect influence on PPVT gains, since the test was not administered with sign and only six of the patients were in total communication programs.

Despite the absence of a control group of unimplanted subjects, indirect comparisons can be made with studies of PPVT improvement in hearing aid users. The postoperative learning rates reported in this study exceed those reported by Geers and Moog (1988) and Boothroyd et al. (1991) (see Introduction and Table 1). It should be noted that the present study looks at progress over time since implantation for each patient, whereas the hearing aid studies discuss "group" rates of progress (averaging the single PPVT scores for a number of children of different ages who are grouped either according to hearing loss or auditory perceptual skills). The preoperative learning rates reported in this study are very close to those reported for the other groups of hearing aid users.

The age at onset of the hearing loss and the duration of profound deafness have been reported to be significant predictors of perceptual performance (Blamey et al., 1992; Osberger et al., 1991; Staller et al., 1991). Similarly for this group of patients, shorter duration of profound deafness and younger age at implantation were significantly associated with better perception scores. Duration of deafness was highly associated with age at implantation, since the patients' hearing losses were predominantly congenital.

The variance among patients in vocabulary growth postimplantation was not significantly accounted for by these factors nor by duration of implant use, perception performance, or communication mode. The absence of a correlation between perception and PPVT improvement cannot be generalized to open-set perception, where the vocabulary used will probably have a direct effect on the perception scores. Age at implantation was significantly correlated with the most recent postoperative equivalent age score $(r=0.402, p<0.05)$. This is to be expected since normally hearing children's scores on the PPVT increase as a function of age and age at implantation was highly correlated with the patients' chronological ages at the most recent assessment. Age at implantation was not, however, a significant predictor of rate of PPVT change. In fact the correlation of this variable with rate was positive and opposite in direction to its relationship with perception. Although communication mode was not a significant predictor of PPVT performance for this group of patients, there were only a small number of children using total communication in the educational setting and this result should not be generalized to other groups of children.

\section{Future Research Directions}

The results of the present study add weight to the suggestions from previous studies that cochlear implants may facilitate the acquisition of receptive vocabulary in some children and adolescents. The children actually achieving age-appropriate language levels still form a small proportion of the total number of implant users, however. The differences in performance among patients are not well explained by the factors; duration of implant use, age at implantation, duration of hearing loss, communication mode, age at onset of profound loss, and closed-set word perception. Further long-term studies which control these variables will be necessary before reasonable language goals and expectations can be set for the majority of implanted children.

\section{ACKNOWLEDGMENTS:}

The authors gratefully acknowledge the financial support of the Lions International Deafness Research Fellowship, the National Health and Medical Research Council of Australia, the Australian Research Council through the Human Communication Research Centre, and the Australian Bionic Ear and Hearing Research Institute. Many thanks also to the parents of the children involved and the teachers at Glendonald School for Deaf Children, St. Mary's School for Children with Impaired Hearing, Westbourne Grammar School, John Pierce Centre's Education Program for Hearing-impaired Children, Taralye Centre's preschool Services for normally hearing and hearing-impaired children, the deafness unit at Banksia College and Yarra Valley School Hearing Unit, as well as the teachers working with children in mainstream educational settings. The help of Louise Brown, Peter Busby, Robert Cowan, Richard Dowell, Karyn Galvin, Rodney Hollow, Gaye Nicholls, Terry Nienhuys, Pauline Nott, Gary Rance, Louise Rowland, and Julia Sarant in the planning and collection of data is gratefully acknowledged. Emily Tobey and Marietta Paterson provided helpful comments in drafting the manuscript.

Address correspondence to: Ms. Pam Dawson, M.Sc., Dip. Aud., Australian Bionic Ear and Hearing Research Institute, 384-388 Albert St., East Melbourne 3002 Australia.

Received June 16, 1993; accepted October 26, 1994

\section{ReFerences}

Blamey, P. J., Dowell, R. C., Clark, G. M., \& Seligman, P. M. (1987). Acoustic parameters measured by a formant-estimating speech processor for a multiple-channel cochlear implant. Journal of the Acoustical Society of America, 82, 38-47.

Blamey, P. J., Pyman, B. C., Gordon, M., Clark, G. M., Brown, A. M., Dowell, R. C., \& Hollow, R. D. (1992). Factors predicting 
postoperative sentence scores in postlinguistically deaf adult cochlear implant patients. Annals of Otology, Rhinology \& Laryngology, 101, 342-348.

Blamey, P. J. \& Tartter, V. C. (1992). Fricative perception by cochlear implant users. Proceedings of 4th Australian International Conference on Speech Science and Technology, Brisbane (pp. 678-683).

Boothroyd, A., Geers, A. E., \& Moog, J. S. (1991). Practical implications of cochlear implants in children. Ear and Hearing, $12,81 \mathrm{~S}-89 \mathrm{~S}$.

Busby, P. A., Tong, Y. C., Roberts, S. A., Altidis, P. M., Dettman, S. J., Blamey, P. J., Clark, G. M., Watson, R. K., Nicholls, G. H., Dowell, R. C., \& Rickards, F. W. (1989). Results for two children using a multiple-electrode intracochlear implant. Journal of the Acoustical Society of America, 86, 2088-2102.

Byrne, D. (1977). The speech spectrum: Some aspects of its significance for hearing aid selection and evaluation. British Journal of Audiology, 11, 40-46.

Clark, G. M., Blamey, P. J., Busby, P. A., Dowell, R. C., Franz, B. K.-H., Nicholls Musgrave, G., Nienhuys, T. G., Pyman, B. C., Roberts, S. A., Tong, Y. C., Webb, R. L., Kuzma, J. A., Money, D. K., Patrick, J. F., \& Seligman, P. M. (1987). A multipleelectrode cochlear implant for children. Archives of Otolaryngology Head and Neck Surgery, 113, 825-828.

Cowan, R. S. C., Blamey, P. J., Galvin, K. L., Sarant, J. Z., Alcantara, J. I., \& Clark, G. M. (1990). Perception of sentences, words, and speech features by profoundly hearing-impaired children using a multi-channel electrotactile speech processor. Journal of the Acoustical Society of America, 88, 1374-1384.

Dawson, P. W., Blamey, P. J., Rowland, L. C., Dettman, S. J., Clark, G. M., Busby, P. A., Brown, A. M., Dowell, R. C., \& Rickards, F. W. (1992). Cochlear implants in children, adolescents, and prelinguistically deafened adults: Speech perception. Journal of Speech and Hearing Research, 35, 401-417.

de Quiros, J. B. (1980). Influence of hearing disorders on language development. Folia Phoniatrica, 32, 103-118.

Dowell, R. C., Whitford, L. A., Seligman, P. M., Franz, B.-K. H., \& Clark, G. M. (1990). Preliminary results with a miniature speech processor for the 22-electrode Melbourne/Cochlear hearing prosthesis. Proceedings of XIV World Congress of Otorhinolaryngology, Head and Neck Surgery, Madrid (pp. 1167-1173). T. Sacristan, J. J. Alvarez-Vicent, J. Bartual, F. Antoli-Candela, et al. (Eds.), Amsterdam: Kugler \& Ghedini.

Dowell, R. C., Dawson, P. W., Dettman, S. J., Shepherd, R. K., Whitford, L. A., Seligman, P. M, \& Clark, G. M. (1991). Multichannel cochlear implantation in children: A summary of current work at the University of Melbourne. American Journal of Otology, 12(Suppl.), 137-143.

Dunn, L. M., \& Dunn, L. M. (1981). Peabody Picture Vocabulary Test-Revised. Circle Pines: American Guidance Service.
Geers, A. E., \& Moog, J. S. (1988). Predicting long-term benefits from single-channel cochlear implants in profoundly hearing-impaired children. American Journal of Otology, 9, 169-176.

Geers, A. E., \& Moog, J. S. (1991). Evaluating the benefits of cochlear implants in an education setting. American Journal of Otology, 12(Suppl.), 116-125.

Hasenstab, M. S. \& Tobey, E. M. (1991). Language development in children receiving Nucleus multi-channel cochlear implants. Ear and Hearing, 12, 55S-65S.

Kirk, K. I., \& Hill-Brown, C. (1985). Speech and language results in children with a cochlear implant. Ear and Hearing, 6, $36 \mathrm{~S}-47 \mathrm{~S}$.

Luxford, W. M., House, W. F., Hough, J. V. D., Tonokawa, L. L., Berliner, K. I., \& Martin, E. (1988). Experiences with the Nucleus multi-channel cochlear implant in three young children. Annals of Otology Rhinology and Laryngology, 97, 14-16.

Mecklenburg, D. J., Blamey, P. J., Busby, P. A., Dowell, R. C., Roberts, S., \& Rickards, F. W. (1990). Auditory (re)habilitation for implanted deaf children and teenagers. In G. M. Clark, Y. C. Tong, \& J. F. Patrick (Eds.), Cochlear Prostheses (pp. 207-221). Edinburgh: Churchill Livingstone.

Nober, E. H., \& Nober, L. W. (1977). Effects of hearing loss on speech and language in the post-babbling stage. In B.F. Jaffe (Ed.), Hearing Loss in Children. Baltimore: University Park Press.

Osberger, M. J., Miyamoto, R. T., Zimmerman-Phillips, S., Kemink, J. L., Stroer, B. S., Firszt, J. B., \& Novak, M. A. (1991). Independent evaluation of the speech perception abilities of children with the Nucleus 22-channel cochlear implant system. Ear and Hearing, 12, 66S-80S.

Plant, G. (1984). A diagnostic speech test for severely and profoundly hearing-impaired children. Australian Journal of Audiology, 6, 1-9.

Quigley, S. P., \& Paul, P. V. (1984). Language and Deafness. San Diego: College-Hill Press.

Robbins, A. M., Osberger, M. J., Miyamoto, R. T., Renshaw, J. J., \& Carney, A. E. (1988). Longitudinal study of speech perception by children with cochlear implants and tactile aids: Progress report. Journal of the Academy of Rehabilitative Audiology, 21, 11-28.

Rowland, L. C., Dawson, P. W., Dettman, S. J., \& Clark, G. M. (1992). Children's habilitation programme. Melbourne Cochlear Implant Clinic.

Staller, S. J., Dowell, R. C., Beiter, A. L., \& Brimacombe, J. A. (1991). Perceptual abilities of children with the Nucleus 22channel cochlear implant. Ear and Hearing, 12, 34S-47S.

Tyler, R. S. (1990). Speech perception with the Nucleus cochlear implant in children trained with the auditory/verbal approach. American Journal of Otology, 11, 99-107. 


\section{University Library}

\section{- M M N E R VA A gateway to Melbourne's research publications}

Minerva Access is the Institutional Repository of The University of Melbourne

Author/s:

Dawson, P. W.;Blamey, P. J.;Dettman, S. J.;Barker, E. J.;Clark, Graeme M.

Title:

A clinical report on receptive vocabulary skills in cochlear implant users

Date:

1995

Citation:

Dawson, P. W., Blamey, P. J., Dettman, S. J., Barker, E. J., \& Clark, G. M. (1995). A clinical report on receptive vocabulary skills in cochlear implant users. Ear and Hearing, June, 16(3), 287-294.

Persistent Link:

http://hdl.handle.net/11343/27480 